\author{
Н. Н. Нижнева, Н. Л. Нижнева-Ксенофонтова, В. А. Ксенофонтов \\ Белорусский государственный университет, Минск
}

\title{
ПРОБЛЕМЫ ОРГАНИЗАЦИИ ПЕДАГОГИЧЕСКОЙ ДЕЯТЕЛЬНОСТИ В СОВРЕМЕННЫХ УСЛОВИЯХ
}

\begin{abstract}
SUMMARY
Problems of organization of pedagogical activities under modern conditions

Some questions of pedagogical activities organization are discussed in the article. The importance of self-government under conditions of information society is described. Different approaches to conflict study, its structure and stages are presented. Causes of pedagogical conflicts and rules of their successful solution are studied. Special attention is paid to the possibilities of stress control that may appear in the process of pedagogical activities.
\end{abstract}

Key words: stress, conflict, self-management, information, pedagogical activities

\section{STRESZCZENIE}

Problemy organizacji działalności pedagogicznej we współczesnych warunkach

W pracy rozpatrywane są niektóre problemy organizacji działalności pedagogicznej. Analizowane są zagadnienia niezbędności autonomii w warunkach społeczeństwa informacyjnego. Pokazane są różnorodne podejścia do badań konfliktu, jego struktury i etapy przebiegu. Rozpatrywane są przyczyny powstawania konfliktów pedagogicznych, a także reguły pozytywnego ich rozwiązywania oraz czynniki temu sprzyjające. Zwraca się uwagę na możliwości kierowania stresem, nieodmiennie powstającym w procesie działalności pedagogicznej. 
В современных условиях педагогической деятельности, когда значительно возрастают потоки информации различного характера (учебная, научная, методическая, воспитательная и др.), важным условием успешности труда преподавателя является умение принимать, перерабатывать, сохранять и передавать информацию, поступающую из различных источников. Возникает потребность анализа информационной пропускной способности преподавателя, когда скорость и объемы поступающей информации превосходят возможности человека по ее приему, анализу и передаче. В условиях перегрузки информацией, кроме психологического дискомфорта в педагогическом труде, это может привести к различным эффектам:

- пропуск информации;

- искажение той или иной информации;

- задержка в передаче определенной информации (при большом потоке необходимо большее время для реагирования);

- фильтрация и анализ потока информации (проблема выбора из поступающих объемов информации только той, которая принадлежат к определенной категории, т.е. классификация и отсеивание остальной);

- приостановка деятельности по разрешению проблемной ситуации ${ }^{1}$.

При поступлении значительного объема информации происходит мобилизация резервов преподавателя, которые направлены на преодоление противоречия между поступающим потоком информации и необходимой и своевременной реакцией на нее. Затем следует определенная корректировка способа деятельности. Эффективность работы может оставаться некоторое время на прежнем уровне. Следовательно, руководителю кафедрального коллектива необходимо ориентироваться на оптимальную и точную передачу информации преподавателям, а им, в свою очередь, для правильной организации личного труда целесообразно овладеть навыками самоменеджмента, т.е. умением эффективно использовать время и рационально организовывать педагогический труд.

Как отмечает профессор А. П. Панфилова, самоуправление - трехмерный процесс, включающий компоненты: умение использовать время, управление записями, управление стрессом².

1 М. А. Кремень, Практическая психология управления: пособие для студентов вузов, Минск 2011.

2 А. П. Панфилова, Имидж делового человека: учебное пособие, Санкт-Петербург 2007, s. 359. 
Важнейшей компонентой самоменеджмента преподавателя является умение управлять записями. Образовательный процесс требует определенного количества записей, помогающих систематизировать собранные данные, их хранить и своевременно представлять. Такие записи у преподавателя могут включать: различные учебно-методические материалы для проведения занятий; выполняемую индивидуальную нагрузку; основные результаты учебной, методической, научной и воспитательной работы; текущие результаты успеваемости студентов; указания заведующего кафедрой; а также инновационные идеи, которые почерпнуты на научных и научно-практических конференциях, научных семинарах и других мероприятиях для использования в образовательном процессе и научной деятельности.

«При прослушивании публичной информации (лекции, доклада, сообщения, речи и пр.) полезно фиксировать следующие пять элементов выступления:

- основные мысли выступающего и наиболее выдающиеся факты, приводимые им;

- свои собственные мысли, идущие по ассоциации, параллельно с мыслями выступающего;

- вопросы, которые хотите задать;

- всякого рода справки, цифры и ссылки докладчика. Именно они усиленно помогают нам впоследствии широко и глубоко проработать тему;

- записывать следует сокращенно, пользуясь условными знаками» ${ }^{3}$.

Как показывает педагогическая практика, эффективный самоменеджмент предполагает своевременное заполнение документов по учету выполненной нагрузки, а также постоянную фиксацию результатов успеваемости студентов. Также систематически требуется ведение записей результатов научной деятельности. Важным представляется письменное ведение учета научных и научно-методических мероприятий, в которых планируется принимать участие на протяжении учебного года.

В условиях информационного общества целесообразно вести записи c помощью персонального компьютера, ноутбука, нетбука, планшета, смартфона в электронном виде с обязательной их систематизацией по видам деятельности. Это позволит оперативно актуализировать необходимую информацию, своевременно внести в нее коррективы и представить по требованию. Опыт показывает, что плановое и систематическое ведение

3 Там же, s. 373. 
собственных записей позволяет не только экономить время, своевременно их обновлять, но также не испытывать дискомфорт в случаях, когда время реакции на те или иные указания, распоряжения ограничено. Порядок и система в управлении записями преподавателя позволяет работать системно.

Успешная педагогическая деятельность предполагает эффективное разрешение возможных конфликтных ситуаций.

Конфликты существовали с древнейших времен, писатели и философы еще несколько тысяч лет назад пытались понять природу конфликтов, раскрыть причины напряженности между людьми и отыскать пути преодоления конфликтов.

Л. Козер указывал, что конфликты выступают как механизм поддержания и изменения внутреннего баланса сил, служат средством определения их взаимного соотношения, выявляют реальный потенциал каждого из оппонентов, после чего устанавливается новое равновесие между ними; это механизм соединения сторон, создания союзов и коалиций.

В современной науке конфликт рассматривается как неотъемлемая характеристика жизни общества, принципиально неустранимое, нормальное явление, которое может иметь как деструктивные, так и конструктивные последствия. Конфликт выполняет целый ряд позитивных функций. Это источник развития, сигнал к изменениям. Конфликтом необходимо управлять, переводя его в конструктивное русло и предупреждая возможные деструктивные последствия ${ }^{4}$.

Конфликт отражает столкновение противоположно направленных, несовместимых потребностей, мотивов, интересов, мыслей, чувств, актов поведения.

Основное отличие конфликта от противоречия заключается в силе эмоционального накала противостояния, остроте негативных переживаний преподавателя и обучающихся - гнева, оскорбленного достоинства, унижения, страха, ненависти и т.п., а потому и особой трудности разрешения.

Различные конфликты, возникающие в учреждениях образования, создают неблагоприятный морально-психологический климат в коллективах, отвлекают внимание сотрудников от профессиональных обязанностей, отражаются на результатах образовательной деятельности.

Важнейшей характеристикой преподавателя является умение конструктивно общаться, не создавая конфликтных ситуаций, а в случае их возникновения - умение грамотно анализировать и разрешать конфликт.

4 Н. В. Гришина, Психология конфликта: учебник для вузов, Санкт-Петербург 2000. 
Прежде всего, преподавателю необходимо знать, что представляет собой конфликт, какова его структура, какие факторы влияют на его возникновение в процессе педагогического взаимодействия и как поступать в конфликтной ситуации.

Существуют различные подходы к изучению конфликта.

Теория кооперации и конкуренции М. Дойча предполагает, что характер конфликта и его исход во многом зависит от мотивационных ориентаций его участников. Согласно модели «двойного интереса», в конфликте присутствуют «свой интерес» и «интерес другого».

Дойч указал, что наиболее распространенными в противоречивой ситуации являются три мотивационных ориентации:

- кооперативная ориентация, при которой участник конфликта отстаивает не только свои интересы, но считает значимыми и стремится удовлетворить интересы оппонента;

- при индивидуалистической мотивационной ориентации участники конфликта признают значимыми только свои интересы; будут ли удовлетворены интересы оппонентов, и, если да, то в какой степени, не имеет значения;

- в случае конкурентной ориентации человек стремится победить оппонента и удовлетворить свои интересы вопреки интересам оппонента.

Дойч отмечал два возможных пути развития конфликта:

- деструктивный;

- конструктивный.

Конфликт часто ассоциируется с войнами, беспорядками, насилием и разрушением. Вместе с тем, он может стать источником развития личности и коллектива.

К структурным элементам конфликта относятся: инцидент, стороны конфликта, предмет конфликта, мотивы конфликта, позиции конфликтующих сторон, конфликтогены, исход конфликта.

Этапы протекания конфликта:

а) возникновение противоречия;

б) его осознание;

в) конфликтное взаимодействие. Выделяют следующие стили поведения в конфликте:

- стиль уклонения - игнорирование проблемы, стремление избежать взаимодействия с партнером по общению в связи с возникшими разногласиями. Не отстаиваются собственные интересы, не рассматриваются интересы оппонента; 
- стиль приспособления - человек отказывается от собственных интересов в пользу интересов партнера. Данный стиль преподаватель может использовать в случае необходимости в приспособлении к индивидуальному своеобразию студентов с целью гармонизации межличностных отношений;

- стиль доминирования - стремление отстоять свою позицию без учета интересов оппонента;

- стиль сотрудничества предполагает выработку взаимовыгодного решения, полностью удовлетворяющего интересы обеих сторон. В процессе сотрудничества педагог предоставляет возможность открыто высказывать свою точку зрения, видеть и находить альтернативные способы решения проблемы;

- стиль компромисса предполагает поиск решения, частично удовлетворяющего обе стороны конфликта на основе взаимных уступок. Использование компромисса при регулировании педагогических конфликтов свидетельствует о подлинном уважении личности студента.

г) поиски способов урегулирования;

д) разрешение конфликта. О полном разрешении конфликта можно говорить лишь в случае удовлетворения интересов обеих сторон. В противном случае сохраняется неудовлетворенность исходом конфликта,ионможетразгоретьсясновойсилой,трансформироваться и перерасти в новый конфликт. При любом исходе конфликта напряженность в отношениях между его участниками сохраняется некоторое время.

Педагогический конфликт является отражением противоречивости совместной деятельности. Исключающими конфликты является лишь взаимно положительно направленные отношения.

Преодоление внутренних и внешних противоречий служит источником личностного совершенствования и студентов, и педагога. По закону диалектики, внутренние противоречия разрешаются через внешние.

В свою очередь внешние противоречия имеют свойства трансформироваться во внутренние, порождая состояние психологического дискомфорта и угнетенности. Поэтому педагогическое руководство преодолением внешних противоречий требует постоянного внимания к эмоциональному самочувствию участников конфликта.

Контролируемые противоречия играют позитивную роль, стимулируя переход субъектов общения из одного качественного состояния (интеллектуального, эмоционального, волевого) в другое, способствуя совершен- 
ствованию межсубъектного взаимодействия. Умелое преодоление противоречий сближает преподавателя и студентов, ведет к взаимопониманию. Гармонизация взаимоотношений помогает обретению общих интересов и совпадению целей.

Игнорирование педагогом стремлений и потребностей студентов, их актуальных переживаний и настроений провоцирует недисциплинированность, внутреннее и внешнее сопротивление реализации педагогических целей ${ }^{5}$.

Преодоление противоречий, с которыми педагог сталкивается в процессе педагогического взаимодействия, требует высокой коммуникативной компетентности.

Ее доминантой является использование гуманистических технологий, отказ от авторитарности, организация демократического общения, когда разрешение межличностных разногласий опирается не столько на расхождения между сторонами, сколько на поиски единства, того, что может сблизить преподавателя и студентов, ориентация на совместное решение возникающих проблем.

Равнопартнерское субъект-субъектное взаимодействие позволяет объединить процессы образования и воспитания в процессы самообразования и самовоспитания.

Как отмечалось, педагогический конфликт - отражение противоречивости совместной деятельности. Чем она сложнее, тем больше опасность дезинтеграции взаимоотношений. Неизбежность возникновения межличностных противоречий вовсе не означает, что в любом случае они фатально ведут к конфликту.

Далеко не каждый межличностный конфликт педагога со студентами является разрушительным с психологической точки зрения. Как и противоречие, конфликт объединяет позитивные и негативные стороны.

Успешное преодоление конфликта предполагает выбор адекватной технологии управления как единства стратегии и тактики.

Стратегия определяет принципиальную линию поведения педагога, направленную на реализацию образовательных целей.

Тактика, как ее составная часть, детерминирует алгоритм непосредственного взаимодействия, выбор педагогических реакций в конкретной конфликтной ситуации.

5 И. И. Рыданова, Основы педагогики общзения, Минск 1998. 
Стратегия и тактика определяются на основе:

- многостороннего анализа сложившейся ситуации;

- учета личностного своеобразия субъектов;

- специфики объекта и предмета конфликта.

Выбор технологии управления конфликтом в каждом конкретном случае является актом педагогического творчества и зависит от комплекса обстоятельств. К ним относятся:

- индивидуальные и возрастные особенности студентов;

- уровень культуры студентов;

- эмоциональное состояние, особенности темперамента студентов;

- мотивы конфронтации;

- условия протекания конфликта;

- характер сложившихся отношений со студентами;

- индивидуальные особенности педагога;

- профессиональные возможности педагога.

Принципы управления конфликтом:

- объективность, предполагает адекватный анализ конфликтной ситуации;

- конкретный подход требует учитывать специфический характер данного конкретного конфликта;

- гласность предполагает, что все участники осознают конфликтность ситуации;

- оперативность и своевременность;

- демократичность проявляется в возможности всех участников высказать свое мнение и повлиять на принимаемое решение.

Правила разрешения конфликта:

- выявить предмет и источник конфликта, чтобы исключить подмену предмета в процессе конфликта;

- не расширять предмет конфликта, сокращать число претензий, особенно эмоционального характера;

- учитывать динамику развития конфликта;

- необходимо выяснить мнение всех участников конфликта, в том числе и его инициатора. При этом важно обеспечить адекватную оценку обеих сторон, т. е. нельзя переоценивать заслуги одних и недооценивать заслуги других. В конфликте не должно быть явных победителей, чтобы конфликт не развился дальше;

- следует учитывать индивидуальные особенности каждого;

- необходимо создавать «багаж» положительных знаний о другом человеке, чтобы в конфликтной ситуации снизить негативизм по отношению к оппоненту; 
- необходимо следить за прохождением информации по возможности без искажения;

- желательно избегать категоричного тона и резкой формы общения.

Основнымипоказателями конструктивного разрешения педагогических конфликтов являются:

- устранение причины, как профилактика рецидивов конфликта;

- гармонизация общения сближения сторон.

Культура разрешения конфликтов повышает интеллектуальную, эмоциональную и волевую активность взаимодействующих сторон, поднимая межличностные отношения на более высокий уровень.

Эффективное разрешение конфликтов, возникающих в процессе педагогического взаимодействия, предполагает также сформированность у сторон конфликтологической компетентности.

В литературе конфликтологическая компетентность определяется как уровень развития осведомленности о диапазоне возможных стратегий поведения в конфликте и умений реализовывать эти стратегии в конкретной жизненной ситуации.

Не менее значимым в педагогической деятельности является умение управлять стрессом.

Канадский ученый, Ганс Селье, основатель концепции стресса, определил его как «неспецифический ответ организма на любое предъявленное ему требование», причем стрессом является все, что нарушает нормальное взаимоотношение организма со средой» ${ }^{6}$.

«В своем развитии стресс проходит ряд стадий: тревоги, адаптации и истощения. На первой стадии тревоги организм пытается приспособиться к стрессу или преодолеть его. Если стресс-фактор продолжает воздействовать на организм, то наступает вторая стадия - адаптация, на которой удается более-менее компенсировать ущерб от воздействия. Однако пребывание в состоянии стресса не может продолжаться бесконечно долго, так как запасы адаптационной энергии, согласно учению Селье, ограничены. Поэтому, если стрессорный фактор продолжает воздействовать на организм, физиологический стресс сменяется на патологический. Третья фаза стресса - истощение при определенных условиях может сопровождаться повышенной тревожностью» 7 .

Ученые выделяют четыре группы симптомов стресса: физиологические, интеллектуальные, эмоциональные и поведенческие.

6 Ю. В. Щербатых, Психология стресса, Москва 2006, s. 22.

7 Там же, s. 29-30. 
К интеллектуальным признакам стресса относят: преобладание негативных мыслей; трудность сосредоточения; ухудшение показателей памяти; постоянное вращение мыслей вокруг одной проблемы; повышенная отвлекаемость; трудность принятия решений, длительные колебания при выборе; частые ошибки, сбои в вычислениях; пассивность; нарушение логики; импульсивность мышления, поспешные и необоснованные решения; сужение поля зрения, кажущееся уменьшение возможных вариантов действия.

К эмоциональным симптомам относятся: беспокойство, повышенная тревожность; раздражительность; уменьшение чувства уверенности в себе; чувство отчужденности, одиночества; потеря интереса к жизни; снижение самооценки, появление чувства вины или недовольства собой или своей работой.

Поведенческими признаками стресса являются: возрастание ошибок при выполнении привычных действий; более быстрая или, наоборот, замедленная речь; увеличение конфликтных ситуаций; хроническая нехватка времени; уменьшение времени на общение с близкими и друзьями; низкая продуктивность деятельности.

Физиологическими симптомами стресса являются: боли в разных частях тела неопределенного характера, головные боли; повышение или понижение АД; учащенный или неритмичный пульс; повышенная утомляемость; появление аллергии; снижение иммунитета, частые недомогания ${ }^{8}$. Необходимо своевременно выявлять признаки стресса и принимать соответствующие меры.

Работники, занятые в системе образования, в связи с ежедневной необходимостью общаться с большим количеством людей и особенностями профессиональной деятельности, объективно находятся в условиях возникновения постоянного стресса. Одни стараются научиться стрессовые ситуации загонять в определенные рамки, другие позволяют стрессу инициировать гнев и фрустрацию. Обучение тому, как справляться с различными стрессовыми ситуациями в образовательном процессе - существенная часть процесса управления самим собой.

Наукой установлено, что серьезную опасность вызывают не сильные и короткие стрессы, а именно длительные, хотя и не столь сильные. Считается, что кратковременный сильный стресс активизирует человека, «встряхивает» его, после чего все показатели организма возвращаются в норму, а слабый, но длительный стресс вызывает истощение организма, в первую очередь его иммунной системы. Каждый человек имеет определенный запас

8 Там же, s. 18-19. 
адаптационной энергии, и если он ее израсходовал, то неизбежно наступает «фаза истощения» 9.

Стоит помнить, что стрессы серьезно влияют на организм человека, так по оценкам ряда западных экспертов, 70\% заболеваний связаны с эмоциональным стрессом ${ }^{10}$.

Следовательно, нельзя доводить свои стрессы до хронической стадии, необходимо поскорее решать проблемы.

Действие стресса нарушает не только здоровье преподавателя, который его испытывает, но и пагубно сказывается на социальных связях. Во время переживания стресса могут ухудшаться отношения в педагогическом коллективе, взаимоотношения со студентами. Такая ситуация, безусловно, не способствует качественной организации образовательного процесса.

Существует разнообразие причин, которые могут вызвать тревогу, беспокойство и стресс. К наиболее распространенным для педагогической среды можно отнести: чрезмерные нагрузки на работе; умственную и физическую усталость; неудовлетворенность результатами профессиональной деятельности; невозможность реализовать свои научные амбиции; нехватку времени; нерациональное планирование занятий; низкую познавательную активность студентов на занятии и, как следствие, низкие результаты выполнения контрольных заданий.

Распространенной причиной возникновения стресса является критика.

«Оптимальный алгоритм конструктивной критики, вызывающей минимальное сопротивление, можно описать так:

1. Выявление положительного эмоционального отношения к личности.

2. Обнаружение личных эмоциональных переживаний.

3. Формирование побудительной мотивации для нового мышления» ${ }^{11}$.

Это общие причины, которые, как правило, вызывают стресс, но у каждого сотрудника есть свои индивидуальные «болевые точки», воздействие на которые провоцирует стрессовые реакции. Чем точнее и скорее будут проанализированы индивидуальные стрессы, тем скорее будут выработаны возможные способы противодействия им. Поскольку никто из педагогического коллектива не застрахован от стресса, важно научиться противостоять ему. Решение проблемы управления личностными стрессами достаточно сложно в силу того, что не существует единых способов

9 Там же, s. 50.

10 Там же, s. 54.

11 Там же, s. 183. 
избавления от него, и не каждый помогает одинаково разным людям. Сильный стресс может быть вызван не только чисто профессиональными, но и личными причинами.

Более успешными в педагогической деятельности являются люди, научившиеся владеть собой и находящие правильную стратегию в стрессе. Они понимают, что «сбрасывать» стрессовую энергию на коллег или обучающихся не только неэтично, но и непродуктивно: происходит изменение морально-психологического климата на кафедре; нарушаются контакты с коллегами, а, кроме того, такое поведение неизбежно ведет к непродуктивному и напряженному проведению занятий со студентами. Такие сотрудники также хорошо понимают, что направлять стрессовую энергию на самих себя неконструктивно. Проблема все равно не решена. Рационально действующие сотрудники стараются перевести стрессовую энергию в другие формы деятельности, а не направлять ее на окружение или на себя.

С учетом множества факторов, порождающих стресс, в литературе по данной проблеме предлагаются различные возможности, являющиеся ключевыми элементами борьбы со стрессом. Например:

- поддержание здорового и сбалансированного образа жизни;

- установление рационального баланса между домом и работой, домашними заботами, воспитанием детей и профессиональной деятельностью;

- своевременное и эффективное решение проблем, порождающих стресс;

- управление эффективностью труда, способность к сотрудничеству и партнерским отношениям;

- грамотное использование времени, эффективная организация досуга;

- реалистический подход к ожиданиям относительно самого себя и окружающих;

- развитие эмоциональной культуры, снижение эмоциональной нагрузки и обеспечение адекватной эмоциональной поддержки дома и в служебных отношениях;

- позитивное восприятие инноваций, адекватное управление изменениями;

- мониторинг стресса по уровню напряжения, по признакам стрессового состояния, мониторинг причин, провоцирующих стресс; 
- изменение направления мыслей, так называемое «отвлечение» или «переключение» 12 .

Таким образом, успех преодоления межличностных конфликтов обусловлен восприятием любого рассогласования взаимоотношений как достаточно серьезной психолого-педагогической проблемы, а также степенью сформированности конфликтологической компетентности всех участников педагогического взаимодействия. Важнейшей характеристикой участников образовательного процесса является умение преодолевать стресс. Овладение навыками самоменджмента в условиях постоянно увеличивающегося потока информации, а также понимание проблемы сущностного содержания конфликта и стрессовой ситуации - необходимая компонента педагогической компетентности.

\section{Библиография}

Гришина Н. В., Психология конфликта: учебник для вузов, Санкт-Петербург 2000.

Кремень М. А., Практическая психология управления: пособие для студентов вузов, Минск 2011.

Панфилова А. П., Имидж делового человека: учебное пособие, Санкт-Петербург 2007.

Рыданова И. И., Основы педагогики общения, Минск 1998.

Щербатых Ю. В., Психология стресса, Москва 2006.

12 А. П. Панфилова, Имидж делового..., s. 379. 